Article

\title{
Microwave Absorption of Barium Borosilicate, Zinc Borate, Fe-Doped Alumino-Phosphate Glasses and Its Raw Materials
}

\author{
Ashis Kumar Mandal *, and Ranjan Sen \\ Glass Division, CSIR-Central Glass and Ceramic Research Institute, Kolkata 700032, India; \\ E-Mail: rsen@cgcri.res.in \\ * Author to whom correspondence should be addressed; E-Mail: ashismand@gmail.com; \\ Tel.: +91-33-2322-3341; Fax: +91-33-2473-0957.
}

Academic Editors: Manoj Gupta and Luciano Feo

Received: 24 December 2014 / Accepted: 8 May 2015 /Published: 19 May 2015

\begin{abstract}
This study presents microwave absorption of raw materials used in barium borosilicate, Fe-doped alumina phosphate and zinc borate glass. Microwave absorption was investigated for the raw materials $\mathrm{SiO}_{2}, \mathrm{Na}_{2} \mathrm{CO}_{3}, \mathrm{BaCO}_{3}, \mathrm{BPO}_{4}, \mathrm{Al}\left(\mathrm{PO}_{3}\right)_{3}, \mathrm{Mg}\left(\mathrm{PO}_{3}\right)_{2}$, $\mathrm{Al}(\mathrm{OH})_{3}, \mathrm{TiO}_{2}$. The study shows that $\mathrm{SiO}_{2}$ could be heated directly above $1000{ }^{\circ} \mathrm{C}$ within $30 \mathrm{~min}$ at $1.5 \mathrm{~kW}$ microwave output (MW) power and $0.8 \mathrm{~kW}$ MW power is necessary to initiate heating (from $260{ }^{\circ} \mathrm{C}$ ). Microwave heating of material with low dielectric loss has been investigated by increasing MW power. Microwave absorption of above glass systems has also been investigated. Dielectric properties such as loss tangent of glass as a function of temperature are presented. Glass melting under direct microwave heating was demonstrated for the studied glass systems. Temperature-Microwave power-Time (T-P-t) profiles for the three glasses indicate maximum MW output power $\sim 1 \mathrm{~kW}, 0.65 \mathrm{~kW}$ and $\sim 1 \mathrm{~kW}$ for barium borosilicate, zinc borate glass and alumino-phosphate glass for $60 \mathrm{~g}$ glass melting.
\end{abstract}

Keywords: microwave absorption; loss tangent; zinc borate glass; barium borosilicate; alumino-phosphate glass 


\section{Introduction}

Microwave energy is being applied as a new method for high-temperature material processing apart from its different other applications. Use of this energy as material processing is gaining importance mainly due to its faster, cleaner and more economical methods compared to conventional methods. Microwave heating depends on the material dielectric loss factor, frequency and intensity of the electric field within the material. The Dielectric loss ( loss tangent) should be high enough to absorb microwave with the given/available microwave output (MW) power at room temperature at a specific frequency [1,2].

Raw materials used in glass making are broadly classified into three major groups, namely (1) glass former (such as $\mathrm{SiO}_{2}, \mathrm{~B}_{2} \mathrm{O}_{3}, \mathrm{P}_{2} \mathrm{O}_{5}, \mathrm{As}_{2} \mathrm{O}_{5}, \mathrm{GeO}_{2}$, etc.); (2) intermediate (such as $\mathrm{Al}_{2} \mathrm{O}_{3}, \mathrm{PbO}, \mathrm{BeO}, \mathrm{TiO}_{2}$, $\mathrm{ZrO}_{2}$ ) and (3) modifier (i.e., alkali oxides, alkaline earth oxides and transition metal oxide). However, there are other groups of raw materials called colorants and fining agents, which are added to the glass batch in small quantities to achieve the desired color of the glass and to remove the bubbles from the molten glass, respectively [3].

Most of the raw materials of glasses are poor microwave absorbers at room temperature except some of the transition metal oxides, some of the compounds of metal, and a few other materials containing water molecules within the composition of those materials. Silica and commercial glass compositions are virtually transparent to microwave radiation at ambient temperature and at low MW power. A scope of work exists to study the absorption of glass and its raw materials at the higher output power at room temperature.

However, the use of microwave heating for processing of glass has been reported such as melting of tin containing molybdo-phosphate and tungsto-phosphate glass [4], preparation of inorganic glasses [5], Niobium phosphate glasses [6], fast ion conducting glasses [7] and iron phosphate glasses [8]. Preparation of phosphate glass with this route has been explored using precursor like $\mathrm{NH}_{4} \mathrm{H}_{2} \mathrm{PO}_{4} \cdot 2 \mathrm{H}_{2} \mathrm{O}$, $\mathrm{H}_{3} \mathrm{PO}_{4}, \mathrm{NaH}_{2} \mathrm{PO}_{4} \cdot 2 \mathrm{H}_{2} \mathrm{O}$, etc. as these sources of $\mathrm{P}_{2} \mathrm{O}_{5}$ are good microwave absorber [9-11]. However, enormous amounts of evolving gas limit its uses to prepare bulk glass under closed microwave cavity. Other sources of $\mathrm{P}_{2} \mathrm{O}_{5}$ to prepare phosphate glass are meta-phosphate raw materials. Moreover, most of the reported work was carried out based on selective compositions in which substantial amount of microwave absorber is present in the glass composition so as to enhance heating. Hence, various other compositions (with or without microwave absorber as the ingredient of glass) may be explored.

The authors' group is working to develop a glass melting process using microwave energy as an alternative heating route with several glass compositions (melting temperature range $1200-1500{ }^{\circ} \mathrm{C}$ ) with or without microwave absorber as a constituent raw material in glass batch. Different glass systems comprising $\mathrm{SiO}_{2}, \mathrm{~B}_{2} \mathrm{O}_{3}, \mathrm{P}_{2} \mathrm{O}_{5}$ as the main building block in glass matrix for different special applications have been prepared using a microwave heating method [12-15].

The present study reports microwave absorption and thereby heating of raw materials and glasses for barium-borosilicate, alumina-phosphate and zinc-borate glass. Microwave heating of material with low dielectric loss has been investigated by increasing MW power. Dielectric loss tangent of these three glasses is also studied as a function of temperature $\left(\sim 1000^{\circ} \mathrm{C}\right)$. 


\section{Experimental Section}

The barium boro-silicate, zinc borate and Fe-doped alumina phosphate glass were prepared using high purity raw materials. The composition and the raw material used for these glasses are presented in Table 1. The raw materials were taken in an agate pestle for mixing manually to prepare $40 \mathrm{~g}$ to $60 \mathrm{~g}$ homogeneous batch and followed by pressing it to form pellet in a hydraulically operated pellet press. The pellets of the batch were placed in an alumina or a quartz crucible insulated by microwave transparent casket insulating box and placed inside the multimode cavity of $3 \mathrm{~kW}, 2.45 \mathrm{GHz}$ microwave furnace. The top cover of the insulating box was facilitated with a hole of $20 \mathrm{~mm}$ diameter for temperature measurement through a non-contact IR pyrometer $\left(260-1800^{\circ} \mathrm{C}\right)$. Accuracy of temperature measurement was $\pm 0.3 \%$ of the measured value $+1{ }^{\circ} \mathrm{C}$ with adjustable emissivity ( $\varepsilon$ : $0.1-1.0$ ). Microwave output power (MW Power) and temperature were recorded by DAQSOFT software in a separate computer. A separate $\mathrm{kWh}$ meter was also connected to the furnace to monitor mainly consumption of instant electrical power and total power consumption for overall system including utilities. The melting of the studied glass was carried out in air atmosphere. Fumes and hot gas generated during melting of the batch was exhausted out intermittently by a diaphragm pump. Glass melting was carried out within the temperature range $1200-1500{ }^{\circ} \mathrm{C}$ for $1 \mathrm{~h}$. Molten glass was cast into a preheated mold and annealed to eliminate thermal stress. The annealed glasses are termed as BBS, ZBR, FAP for barium borosilicate, zinc borate and iron doped alumina-phosphate glasses, respectively.

Table 1. Batch composition and raw material used for BBS, ZBR and FAP glasses.

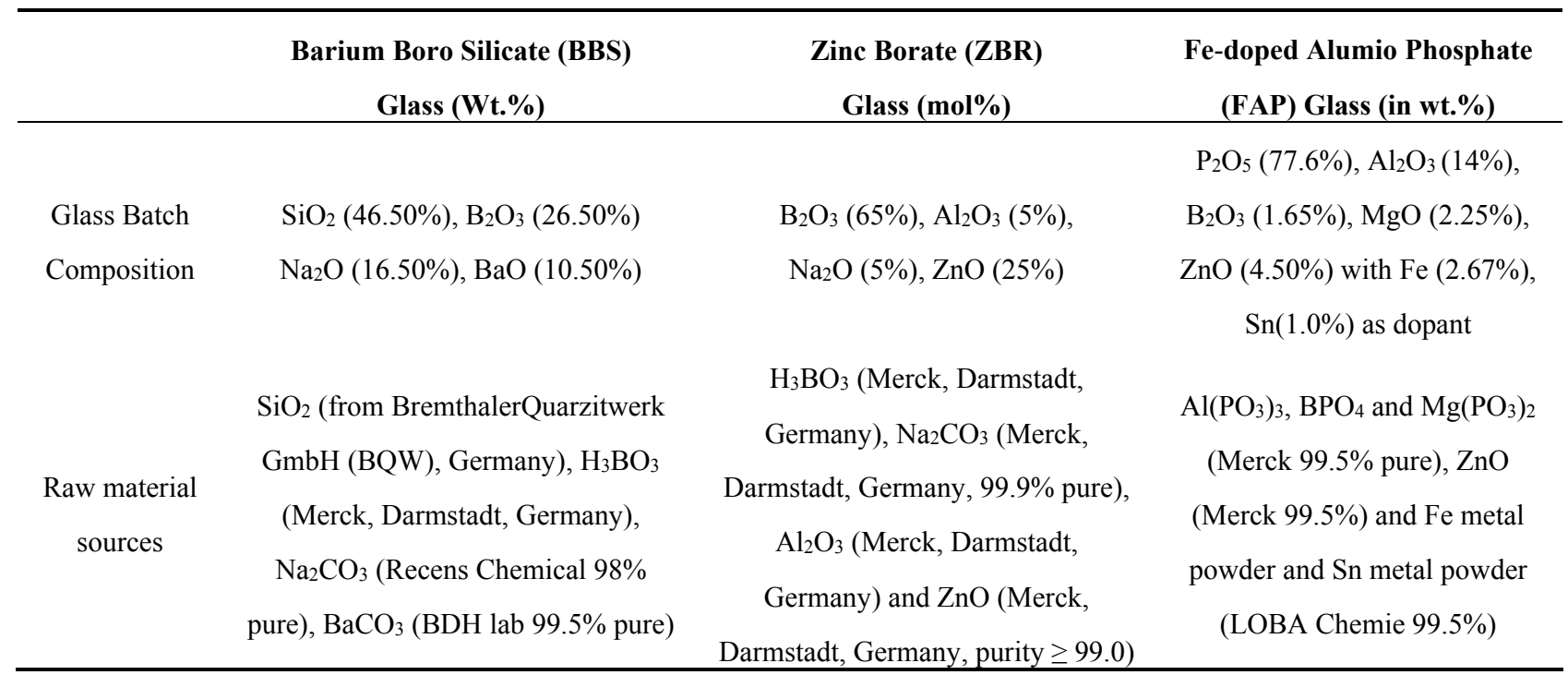

The dielectric loss tangent was measured at $2.45 \mathrm{GHz}$ as a function of temperature (within $1000{ }^{\circ} \mathrm{C}$ ) using a cylindrical cavity, a vector network analyzer, a microwave amplifier, an infrared pyrometer and a computer. The cylindrical rod shape sample was placed inside a quartz tube container and microwaves are applied for heating and measuring simultaneously inside a microwave cavity [16]. The typical uncertainty of these measurements is around $2 \%$ in the real part and $5 \%$ in the imaginary part. At high-temperatures (around $1000{ }^{\circ} \mathrm{C}$ ), the uncertainty can increase to $10 \%$ because the dimensions of the sample change when the materials are melting. The dimension of the sample is a variable used in the dielectric calculations. Loss tangent of FAP glass was measured using the batch. 


\section{Results and Discussion}

\subsection{Microwave Absorption of Raw Material}

Heating with microwave depends on the material dielectric loss factor. Material can be broadly classified into three categories based on dielectric loss factor; (i) microwave absorbers which absorb microwave energy from the electromagnetic field generating heat within it rapidly; (ii) microwave reflector, which reflects microwave (bulk metal and alloy), are therefore used in making microwave guides and cavity; (iii) microwave transmitters which are transparent to microwaves, some of them are fused silica, alumina, Zircon, etc. Many inorganic materials strongly couple with microwave at room temperature and generate heat rapidly in a domestic microwave oven (DMO) operating at $2.45 \mathrm{GHz}$ frequency [17]. The reorientation mechanism of dipoles in the applied alternating electromagnetic field plays an important role for microwave heating. Microwave coupling means that heating is possible when the dipolar reorientation is unable to follow the frequency of the alternating electric field and phase lag developed. This generates polarization current which is in phase with the applied field. The phase lag, field strength and current are denoted as $\delta$, E, and I, respectively. The effective energy dissipation factor or loss tangent, $\tan \delta\left(\tan \delta=\varepsilon^{\prime \prime} / \varepsilon^{\prime}\right)$, is a convenient measure of heating effect which occurs in an applied field. $\varepsilon^{\prime}$ and $\varepsilon^{\prime \prime}$ are the real and imaginary parts of the dielectric constant. In ionic materials, where ion can drift in the applied field, joule heating can occur due to ionic current. Hence, the dipolar reorientation current, $\sigma_{\mathrm{d}}$, and ion drift current, $\sigma_{\mathrm{i}}$, can be combined so that effective loss factor becomes $\varepsilon^{\prime \prime}=\left(\sigma_{d}+\sigma_{i}\right) / \omega \varepsilon_{o}$, where $\varepsilon_{o}$ is dielectric constant of free space. In semiconductors and semi-metallic materials, conduction is dominated by the electron transport. Hence, $\sigma$ (electronic), which increases with both the temperature and decreasing band gap, leads to higher absorption of microwave. The absorbed microwave power per unit volume of material, $\mathrm{P}$, is dependent upon the total current $\sigma$ and the intensity of electric field, E in the sample following Equation (1).

$$
\mathrm{P}=\sigma|\mathrm{E}|^{2}=\left(\omega \varepsilon_{\mathrm{o}} \varepsilon^{\prime \prime}\right)|\mathrm{E}|^{2}=\left(\omega \varepsilon_{\mathrm{o}} \varepsilon^{\prime} \tan \delta\right)|\mathrm{E}|^{2}
$$

K.J. Rao et al. [17] opined that absorption of microwave and thereby heating of glass can only be carried out provided at least one ingredient in the glass should have good dielectric properties to couple with the microwave radiation at room temperature. However, the dielectric property of material changes with temperature. Microwave absorption and thereby heating of major glass constituents or ingredients for the studied glasses were studied individually. Known quantity ( $30 \mathrm{~g})$ of each raw material was formed into the shape of pellet at 4 ton pressure and put in an alumina crucible inside a microwave transparent insulation box without being surrounded by any microwave absorber, and observations are depicted in the following section.

\subsubsection{Dielectric Loss and MW Absorption by $\mathrm{SiO}_{2}$}

Figure 1 demonstrates the loss tangent of $\mathrm{SiO}_{2}$ as a function of temperature (up to $1000{ }^{\circ} \mathrm{C}$ ). Loss tangent can be identified $\sim 0.002$ until $400{ }^{\circ} \mathrm{C}$ from the Figure 1, and thus it is considered as a microwave transparent material. However, it increases at above $500{ }^{\circ} \mathrm{C}$ suggesting improved coupling of the microwave at above this temperature. 


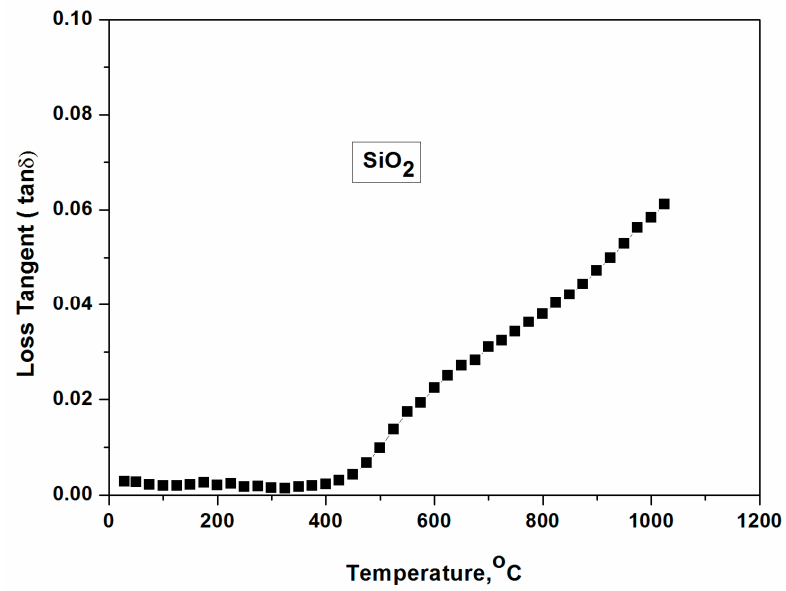

Figure 1. Loss tangent and dielectric constant of $\mathrm{SiO}_{2}$ until $1000^{\circ} \mathrm{C}$.

The microwave absorption of $\mathrm{SiO}_{2}$ was studied with gradually increasing MW power until $1.2 \mathrm{~kW}$ [18]. It has been reported that temperature increases above $0.8 \mathrm{~kW} \mathrm{MW}$ power after $35 \mathrm{~min}$ (with a manual increase of MW power from $0.3 \mathrm{~kW}$ ). $\mathrm{SiO}_{2}$ could be heated to $1400^{\circ} \mathrm{C}$ within $1 \mathrm{~h} 30 \mathrm{~min}$ at $\sim 1 \mathrm{~kW}$ MW power under direct microwave irradiation. To reduce the heating time further, the initial MW power was raised at $0.8 \mathrm{~kW}$ as shown in Figure 2. Heating began (from $260{ }^{\circ} \mathrm{C}$ ) after $10 \mathrm{~min}$ and temperature could be raised above $1000^{\circ} \mathrm{C}$ with a stepwise increase of MW power until $1.5 \mathrm{~kW}$ from $0.8 \mathrm{~kW}$ within 30-35 min. It has been seen in Figure 2 that MW Power required to raise temperature above $500{ }^{\circ} \mathrm{C}$ is $1.5 \mathrm{~kW}$. However, temperature increases spontaneously above $500{ }^{\circ} \mathrm{C}$, without demanding MW power to increase further. This underpins the study of loss tangent which increases above $\sim 500^{\circ} \mathrm{C}$, indicating good microwave absorption by $\mathrm{SiO}_{2}$ above this temperature. Thus, microwave heating can be employed for low lossy material (i.e., low loss tangent or loss factor) by increasing MW power.

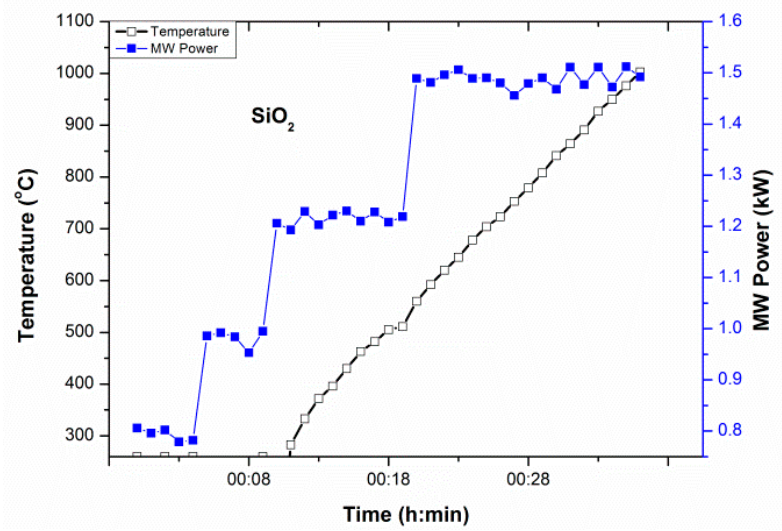

Figure 2. Temperature-microwave power-time (T-P-t) profile of $\mathrm{SiO}_{2}$. The temperature increase was noticed at $0.9 \mathrm{~kW}$ microwave power after 10 min with a manual increase of microwave power from $0.8 \mathrm{~kW}$. 


\subsubsection{MW absorption of $\mathrm{BPO}_{4}$}

Figure 3 depicts T-P-t profile of $\mathrm{BPO}_{4}$, source of $\mathrm{B}_{2} \mathrm{O}_{3}$ and $\mathrm{P}_{2} \mathrm{O}_{5}$ in the glass, under direct microwave irradiation (i.e., without any microwave susceptor/absorber around it). It can be identified that $\mathrm{BPO}_{4}$ absorbs microwaves at $0.8 \mathrm{~kW}$ MW power and temperature above $1000{ }^{\circ} \mathrm{C}$ can be raised under direct microwave heating with $1 \mathrm{~kW} \mathrm{MW}$ power. Time of heating was recorded $1 \mathrm{~h} 30 \mathrm{~min}$. However, time could be shortened by increasing MW power at the beginning of heating. A small amount of susceptor may also be placed around the crucible to reduce the total time.

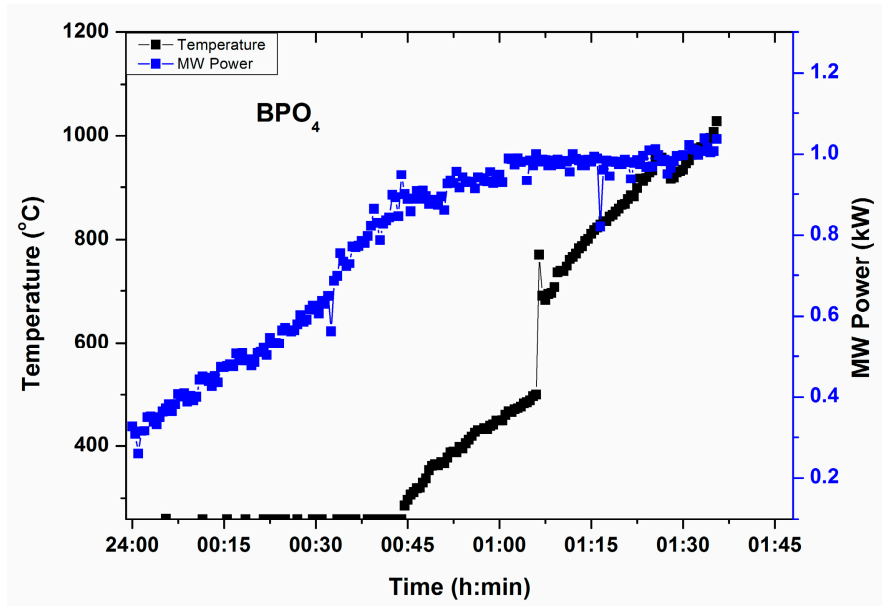

Figure 3. T-P-t profile of $\mathrm{BPO}_{4}$ in absence of microwave susceptor.

\subsubsection{MW Absorption of Meta-Phosphate Raw Material}

Preparation of phosphate glass using meta-phosphate raw material has certain advantages, which includes less handling of material and less frothing during melting due to the absence of $\mathrm{H}_{2} \mathrm{O}$ or other gaseous elements in these raw materials. This restricts evolution of gas, overflowing the molten glass from the crucible as in case of $\mathrm{H}_{3} \mathrm{PO}_{4}, \mathrm{NH}_{4} \mathrm{H}_{2} \mathrm{PO}_{4} 2 \mathrm{H}_{2} \mathrm{O}$.

$\mathrm{Mg}\left(\mathrm{PO}_{3}\right)_{2}$

T-P-t profile of $\mathrm{Mg}\left(\mathrm{PO}_{3}\right)_{2}$, a source of $\mathrm{P}_{2} \mathrm{O}_{5}$ and $\mathrm{MgO}$ in glass, under direct microwave irradiation is presented in Figure 4. Figure 4 displays temperature increase at $0.75 \mathrm{~kW}$ MW Power (stepwise increase of MW power from $0.3 \mathrm{~kW}$ within $1 \mathrm{~h}$ ). This exemplifies that above $0.75 \mathrm{~kW}, \mathrm{Mg}\left(\mathrm{PO}_{3}\right)_{2}$ can be heated directly by microwave. Rapid heating of $\mathrm{Mg}\left(\mathrm{PO}_{3}\right)_{2}$ can be identified $750{ }^{\circ} \mathrm{C}$, from the T-P-t profile in Figure 4, indicating its critical temperature. 


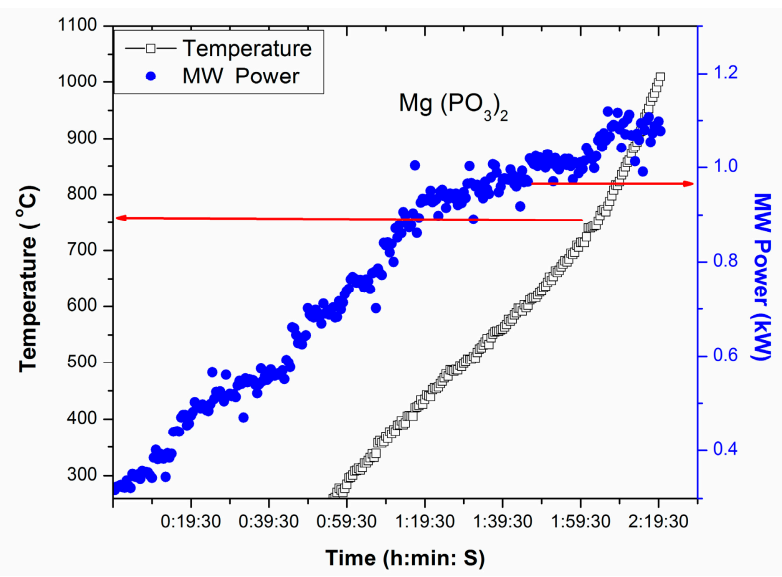

Figure 4. T-P-t profile of $\mathrm{Mg}\left(\mathrm{PO}_{3}\right)_{2}$ under direct microwave irradiation.

$\mathrm{Al}\left(\mathrm{PO}_{3}\right)_{3}$

Figure 5 exhibits T-P-t profile for $\mathrm{Al}\left(\mathrm{PO}_{3}\right)_{3}$, source of $\mathrm{P}_{2} \mathrm{O}_{5}$ and $\mathrm{Al}_{2} \mathrm{O}_{3}$ in glass. T-P-t profile in Figure 5 shows no temperature increase within $30 \mathrm{~min}$ of manual increase of MW Power until $0.9 \mathrm{~kW}$. However, placing a small amount microwave absorber nearby could elevate the temperature as depicted in the inset of Figure 5.

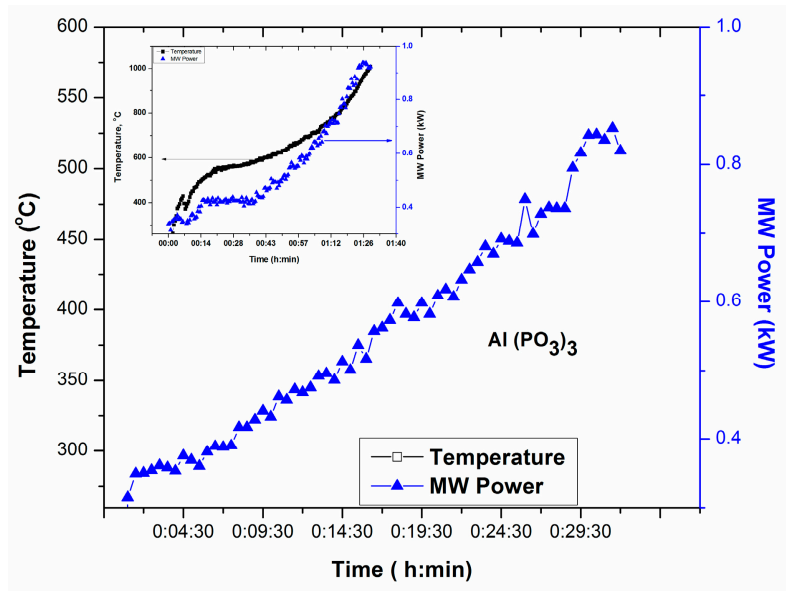

Figure 5. T-P-t profile of $\mathrm{Al}\left(\mathrm{PO}_{3}\right)_{3}$.; Inset shows the increase of temperature in the presence of microwave absorber surrounding the crucible.

\subsection{4. $\mathrm{Al}(\mathrm{OH})_{3}$}

Figure 6 illustrates T-P-t profile of $\mathrm{Al}(\mathrm{OH})_{3}$, source of $\mathrm{Al}_{2} \mathrm{O}_{3}$ in glass, in the presence of microwave susceptor. Direct heating by microwave has been studied and found that $\mathrm{Al}(\mathrm{OH})_{3}$ is a poor microwave absorber at room temperature within $1.0 \mathrm{~kW}$ MW Power. The inset shows no temperature increase with direct microwave radiation until $1.0 \mathrm{~kW}$ MW power. This signifies that $\mathrm{Al}(\mathrm{OH})_{3}$ is poor microwave absorber within $1 \mathrm{~kW}$ MW power. It can be seen from Figure 6 that temperature increases above $600{ }^{\circ} \mathrm{C}$ at $0.9 \mathrm{~kW}$ (within $20 \mathrm{~min}$ ) in the presence of a small microwave absorber. 


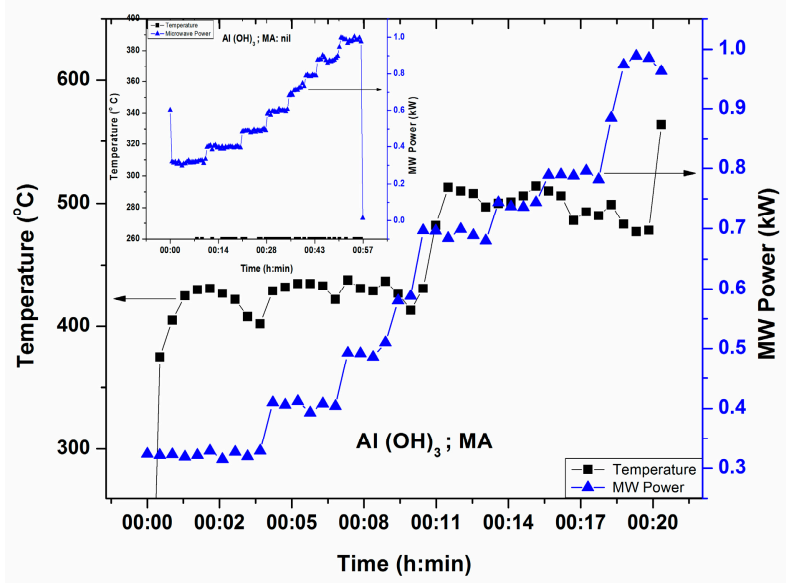

Figure 6. T-P-t profile of $\mathrm{Al}(\mathrm{OH})_{3}$ in presence of microwave susceptor. Inset shows no temperature increase within $1 \mathrm{~h}$ with maximum MW power $1.0 \mathrm{~kW}$ in the absence of microwave susceptor.

\subsection{5. $\mathrm{Na}_{2} \mathrm{CO}_{3}$}

$\mathrm{Na}_{2} \mathrm{CO}_{3}$ is introduced to obtain $\mathrm{Na}_{2} \mathrm{O}$ in the studied glass. $\mathrm{Na}_{2} \mathrm{CO}_{3}$ is found to be a poor microwave absorber until $1.2 \mathrm{~kW}$ (not shown in the figure) at room temperature. However, a small amount of SiC around crucible containing $\mathrm{Na}_{2} \mathrm{CO}_{3}$ could increase the temperature above $1000{ }^{\circ} \mathrm{C}$ as displayed in Figure 7.

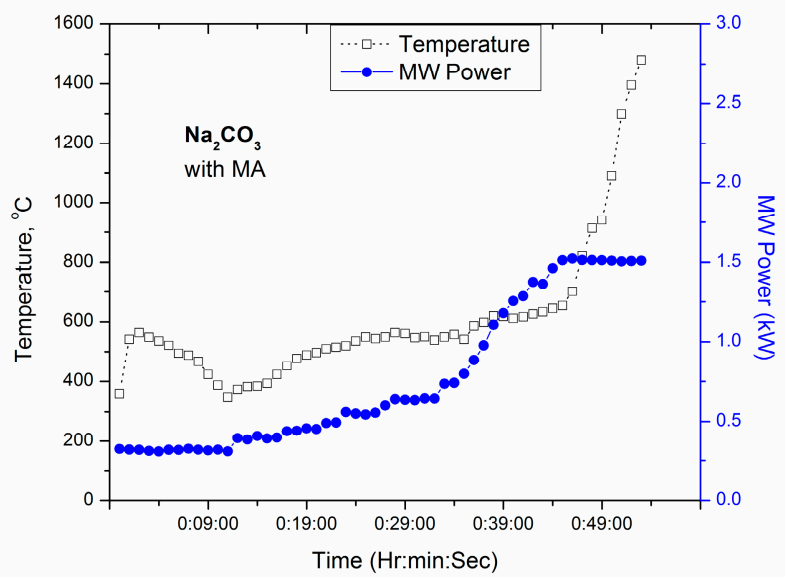

Figure 7. T-P-t profile of $\mathrm{Na}_{2} \mathrm{CO}_{3}$ after $1 \mathrm{~h}$ exposure in microwave cavity with manually increased MW power up to $1.5 \mathrm{~kW}$ in presence of microwave absorber.

\subsection{6. $\mathrm{BaCO}_{3}$}

The source of $\mathrm{BaO}$ in the studied barium boro-silicate glass is $\mathrm{BaCO}_{3}$ and $\mathrm{MW}$ absorption of $\mathrm{BaCO}_{3}$ is demonstrated in Figure 8. Although $\mathrm{BaCO}_{3}$ can be considered as a poor microwave absorber at low MW power at room temperature, it is possible to begin heating (from $260{ }^{\circ} \mathrm{C}$ ) above $1 \mathrm{~kW}$ MW power. Improved microwave coupling and thereby heating were recorded at $\sim 500{ }^{\circ} \mathrm{C}$ and rapid heating above $\sim 700{ }^{\circ} \mathrm{C}$ indicates its critical temperature as seen in Figure 8. Direct heating of $\mathrm{BaCO}_{3}$ above $1300{ }^{\circ} \mathrm{C}$ 
was achieved by a stepwise increase of MW power to $1.3 \mathrm{~kW}$ within $1 \mathrm{~h} 30 \mathrm{~min}$. Total time may be reduced by enhancing MW power at an initial level.

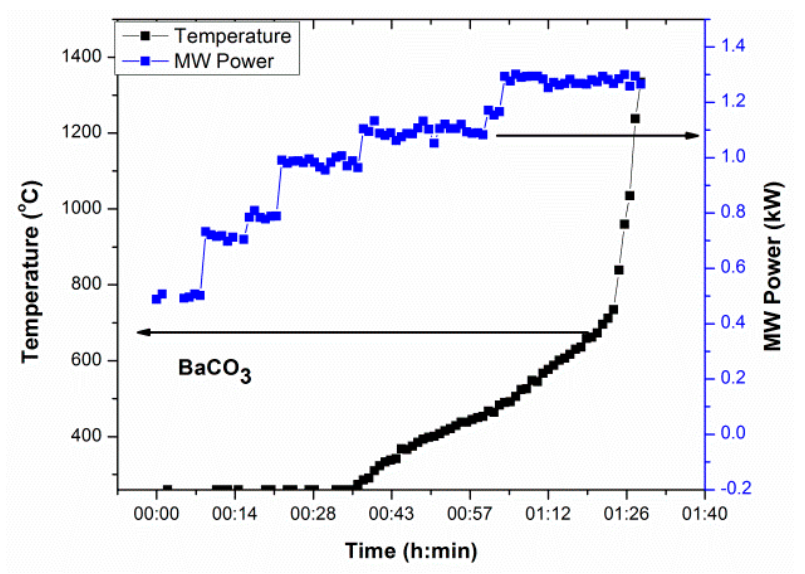

Figure 8. T-P-t profile of $\mathrm{BaCO}_{3}$ under direct microwave radiation.

\subsection{7. $\mathrm{H}_{3} \mathrm{BO}_{3}$}

Microwave absorption of $\mathrm{H}_{3} \mathrm{BO}_{3}$, the source of $\mathrm{B}_{2} \mathrm{O}_{3}$ in glass, was studied in our earlier report [17]. $\mathrm{H}_{3} \mathrm{BO}_{3}$ can be considered as a moderate microwave absorber and couples with microwave at $0.8 \mathrm{~kW}$ MW power at room temperature. The rapid heating of $\mathrm{H}_{3} \mathrm{BO}_{3}$ at $\sim 700{ }^{\circ} \mathrm{C}$ depicts its critical temperature.

\subsection{Dielectric Loss and MW Absorption of Glass}

\subsubsection{Barium Borosilicate Glass}

Figure 9 indicates the dielectric loss tangent of barium borosilicate (BBS) glass as a function of temperature $\left(\sim 1000^{\circ} \mathrm{C}\right)$. It is clearly seen from the figure that loss tangent is virtually merged with the $\mathrm{X}$-axis until $400{ }^{\circ} \mathrm{C}$ indicating poor interaction with microwave within $400{ }^{\circ} \mathrm{C}$. However, it increases above $400{ }^{\circ} \mathrm{C}$ and a sharp increase above $800^{\circ} \mathrm{C}$ signifies its critical temperature.

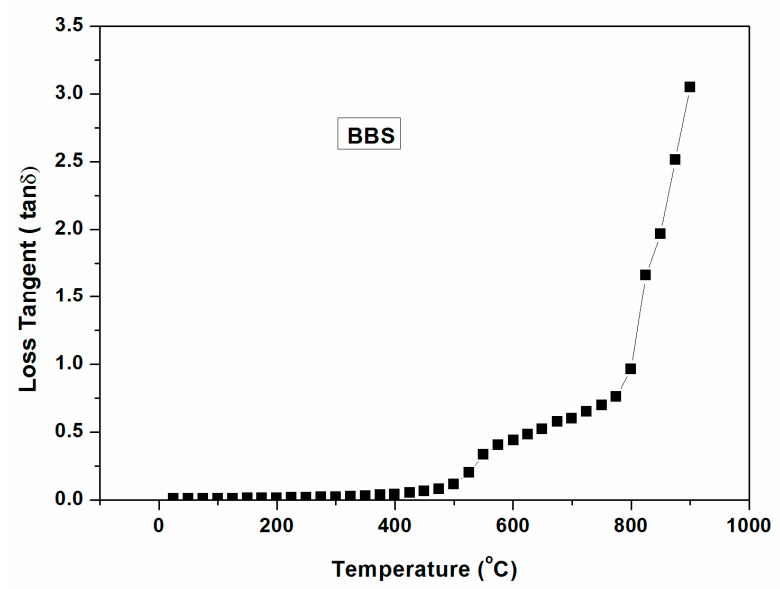

Figure 9. Dielectric loss tangent (with temperature $\sim 1000^{\circ} \mathrm{C}$ ) of barium borosilicate glass. 
T-P-t profile for BBS glass was recorded without placing any microwave susceptor around the crucible, as presented in Figure 10. Figure 10 shows that the BBS glass could not be heated at low temperatures and less MW power $(<1 \mathrm{~kW})$. However, temperature increases at $\sim 1 \mathrm{~kW}$ MW power and above $500{ }^{\circ} \mathrm{C}$ MW power was manually reduced to control the fast heating. Rapid heating is also recorded at $0.35 \mathrm{~kW}$ MW power above $800{ }^{\circ} \mathrm{C}$, corroborating the results from the dielectric loss tangent profile. Microwave interaction with the batch material was found to be different at ambient temperature due to the presence of different raw materials (i.e., carbonate, $\mathrm{H}_{3} \mathrm{BO}_{3}$ ). Sharp increase of temperature was carefully regulated by reducing the MW power to avoid damaging the crucible due to high thermal shock. A transparent annealed glass block (BBS) is presented in Figure 10b. Detailed discussion of glass properties and it comparison with conventional melted glass has been presented elsewhere [15].

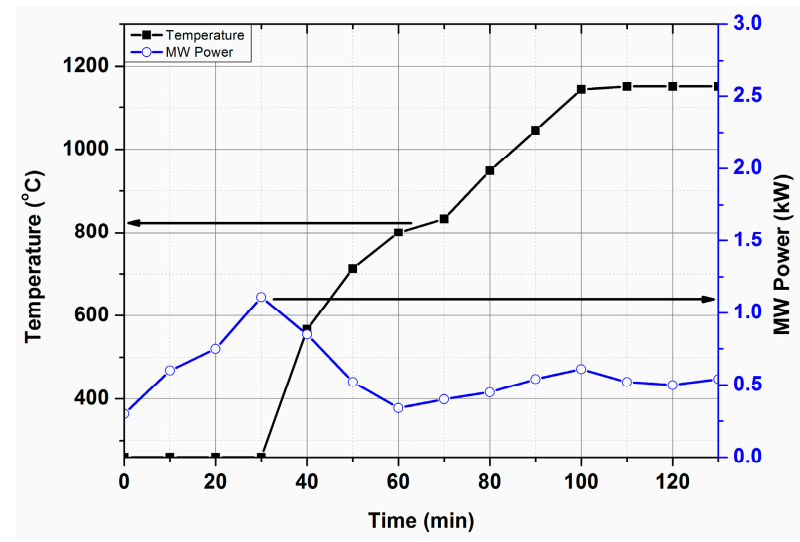

(a)

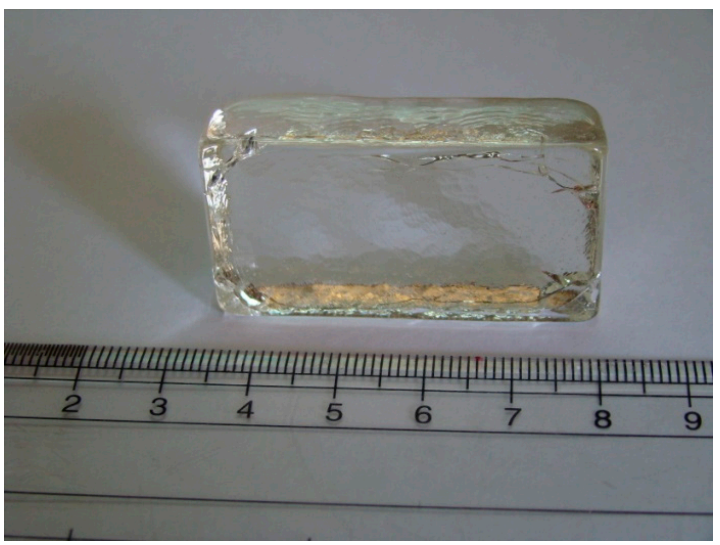

(b)

Figure 10. (a) T-P-t profile of BBS glass batch, (under direct microwave heating). (b) Photograph of annealed BBS glass.

\subsubsection{Zinc Borate Glass (ZBR)}

Dielectric loss tangent of ZBR glass as a function of temperature $\left(\sim 1000^{\circ} \mathrm{C}\right)$ is presented in Figure 11. It can be seen from Figure 11 that loss tangent is virtually merged with the $\mathrm{X}$-axis indicating poor microwave interaction until $400{ }^{\circ} \mathrm{C}$. Above $500{ }^{\circ} \mathrm{C}$, the loss tangent increases and sharp increase of loss tangent is noticed above $700-800^{\circ} \mathrm{C}$, enabling smooth and faster heating with less MW power.

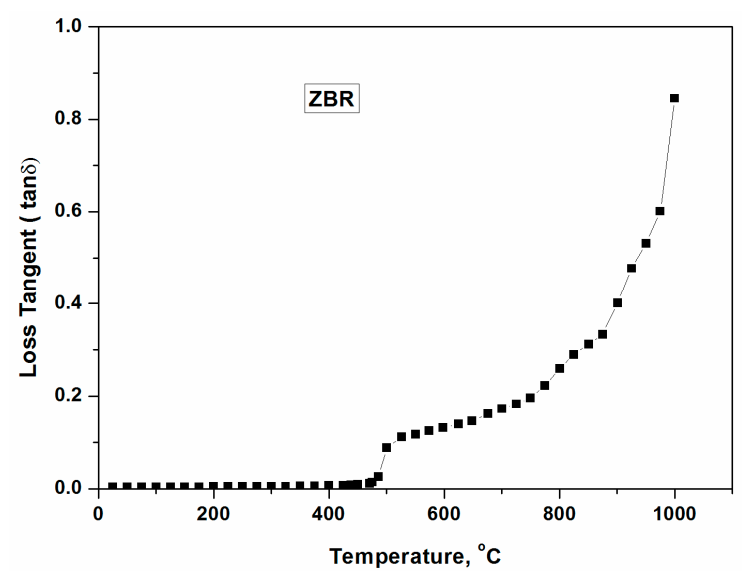

Figure 11. Dielectric loss tangent of ZBR glass until $1000^{\circ} \mathrm{C}$. 
Figure 12a displays T-P-t profile of ZBR glass without placing any microwave absorber around the glass batch. During the direct microwave heating of the batch, it was observed that the glass batch heated up after $10 \mathrm{~min}$. However, an enormous evolution of gases $\left(\mathrm{H}_{2} \mathrm{O}, \mathrm{CO}_{2}\right)$, causing overflow of molten glass from the crucible, damage the insulation set up. To avoid this, the batch was sintered and placed in a crucible surrounding by a small quantity of carbon powder to initiate heating at room temperature. This carbon oxidizes above $500-600{ }^{\circ} \mathrm{C}$ and remains in the form of $\mathrm{CO}_{2}$. Figure $12 \mathrm{~b}$ represents T-P-t profile for ZBR glass (starting with sintered glass batch) in the presence of carbon powder. Hence, T-P-t profile above $600{ }^{\circ} \mathrm{C}$ depicts the microwave absorption of glass batch only. Figure $12 \mathrm{~b}$ shows that the ZBR glass could be heated in the presence of carbon powder at room temperature and less MW power $(<0.4 \mathrm{~kW})$. Faster heating was observed at $0.5 \mathrm{~kW}$ MW power above $700{ }^{\circ} \mathrm{C}$, corroborating the result of dielectric loss tangent profile. Figure 12c shows clear transparent annealed ZBR glass block melted in microwave heating. Detailed discussion of glass properties and its comparison with conventional melted glass has been presented elsewhere [14].

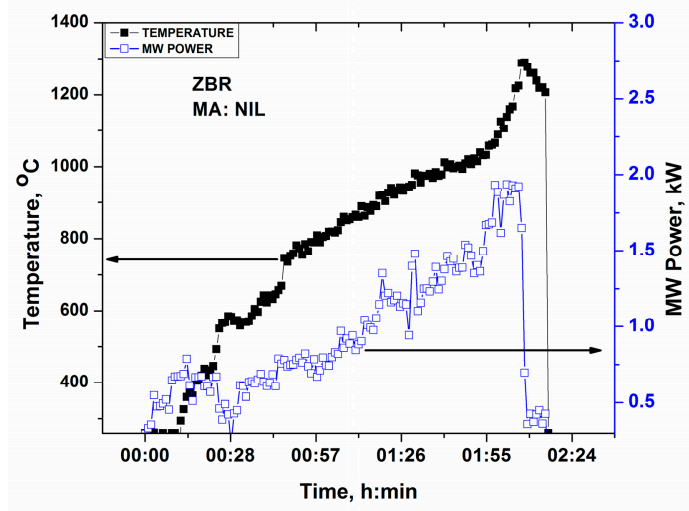

(a)

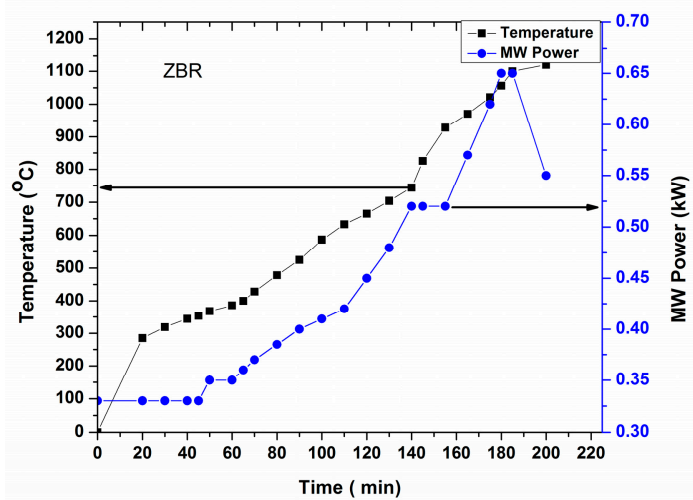

(b)

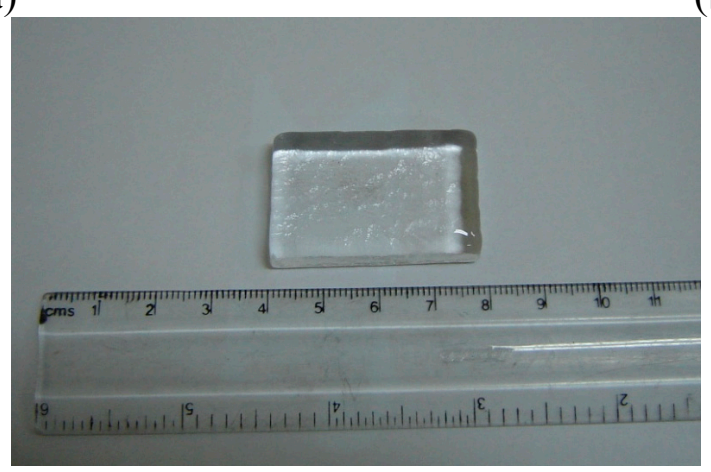

(c)

Figure 12. (a) T-P-t profile for zinc borate glass under direct microwave heating of powder glass batch; (b) T-P-t profile for zinc borate glass under microwave heating of the sintered glass batch with carbon powder around the crucible; (c) Photograph of annealed ZBR glass block melted by microwave heating.

\subsubsection{Fe-Doped Phosphate Glass}

Loss tangent of powdered glass batch with temperature $\left(\sim 1000^{\circ} \mathrm{C}\right)$ is shown in Figure 13. It is seen in the figure that there is no significant change of loss tangent until $400{ }^{\circ} \mathrm{C}$. Loss tangent increases above $400{ }^{\circ} \mathrm{C}$, signifying higher microwave interaction with the glass batch. Thus, microwave heating of the 
glass batch is feasible with low MW power above $400{ }^{\circ} \mathrm{C}$. It is also seen from Figure 13 that the loss tangent increases sharply above $800^{\circ} \mathrm{C}$, enabling direct microwave heating above this temperature with low MW Power.

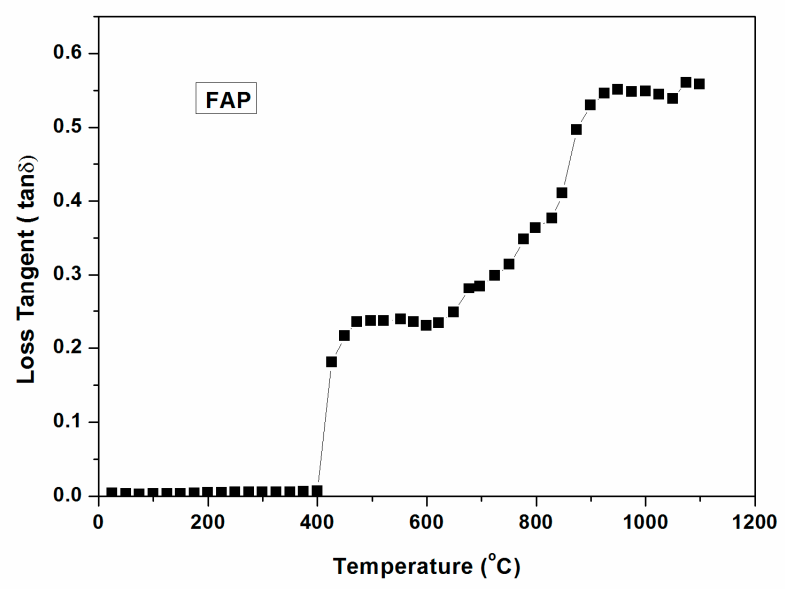

Figure 13. Dielectric loss tangent of FAP powdered glass batch with temperature $\left(\sim 1000{ }^{\circ} \mathrm{C}\right)$.

Figure 14a presents T-P-t profile for FAP glass under direct microwave heating of the pelletized glass batch. Figure 14a shows that temperature increases within $15 \mathrm{~min}$ exposer of glass batch under microwave radiation with a manual increase of MW power within $0.6 \mathrm{~kW}$. It can be clearly seen from the figure that total melting time was within $2 \mathrm{~h}$ and the maximum MW power was $\sim 1 \mathrm{~kW}$ during melting at $1500{ }^{\circ} \mathrm{C}$. However, at maximum temperature, much less MW power $(0.6 \mathrm{~kW})$ is required during holding. It is also seen from the figure that above temperatures of $400{ }^{\circ} \mathrm{C}$, the requirement of MW power becomes less $(<0.4 \mathrm{~kW})$ indicating higher microwave absorption owing to higher dielectric loss tangent above this temperature. This is similar to earlier findings for the dielectric loss tangent profile with temperature. This is due to the addition of iron as metal powders improve microwave absorption [19-22]. Figure 14b displays clear transparent FAP glass block obtained from microwave heating. The investigation of the properties of the glasses and their comparison are in progress and will be presented in future work.

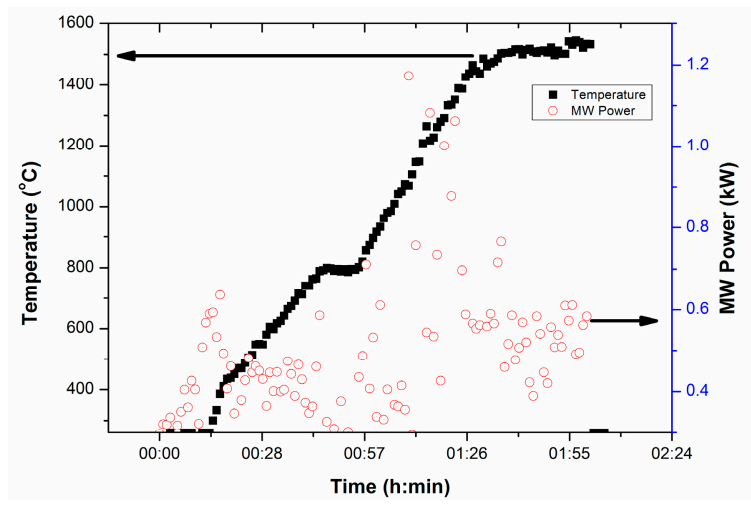

(a)

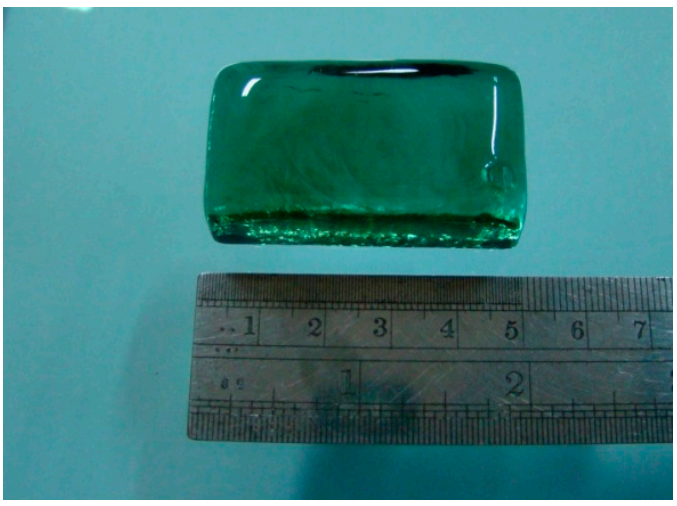

(b)

Figure 14. (a) T-P-t profile for FAP glass under direct microwave heating of peletized glass batch. (b) Photograph of annealed glass melted by microwave heating. 


\section{Conclusions}

Microwave output power plays an important role in microwave heating. Material with low dielectric loss tangent may be heated using higher output power. Thus, glass containing poor microwave absorber can be heated at higher MW power. Three different glass systems such as barium borosilicate, zinc borate and iron doped aluminophosphate glasses have been melted under microwave heating within 1200-1500 ${ }^{\circ} \mathrm{C}$ using alumina/quartz crucible. Dielectric loss tangent of these barium borosilicate, zinc borate and iron doped alumino phosphate glasses show the sudden increase of loss tangent at $550{ }^{\circ} \mathrm{C}$, $400{ }^{\circ} \mathrm{C}$ and $450{ }^{\circ} \mathrm{C}$, respectively. Microwave absorption of raw material like $\mathrm{SiO}_{2}, \mathrm{Na}_{2} \mathrm{CO}_{3}, \mathrm{BaCO}_{3}$, $\mathrm{H}_{3} \mathrm{BO}_{3}, \mathrm{BPO}_{4}$, aluminium meta-phosphate, $\left[\mathrm{Al}\left(\mathrm{PO}_{3}\right)_{3}\right]$, magnesium meta-phosphate $\left[\mathrm{Mg}\left(\mathrm{PO}_{3}\right)_{2}\right]$, $\mathrm{Al}(\mathrm{OH})_{3}$ is studied. $\mathrm{SiO}_{2}$ could be heated above $1000{ }^{\circ} \mathrm{C}$ within $30 \mathrm{~min}$ at $1.5 \mathrm{~kW}$ microwave output power with $0.8 \mathrm{~kW}$ minimum output power needed to initiate heating (from $260{ }^{\circ} \mathrm{C}$ ). The maximum MW output power needed for glass melting is $1.2 \mathrm{~kW}$ for barium borosilicate, $\sim 1 \mathrm{~kW}$ for iron doped aluminophosphate and $0.65 \mathrm{~kW}$ for zinc borate glass system. T-P-t profiles for the three glasses indicate the maximum time required for laboratory glass melting is $2 \mathrm{~h}$. Hence, microwave energy can be successfully utilized to produce bulk glasses on a small scale, consuming much less energy and taking much less time than needed in conventional glass melting.

\section{Acknowledgments}

This work was funded by Supra Institutional Network Project ESC0202 (GLASSFIB) of Council of Scientific and Industrial Research, India. Authors are thankful to the Director, CSIR-CGCRI for his kind support and encouragement to pursue this work.

\section{Author Contributions}

Ashis Kumar Mandal designed the research, performed the experiments, processed the data together with Ranjan Sen and wrote the manuscript. Ranjan Sen guided during the research design, planning and procurement and helped during data processing and also overall advice with correction of manuscript. All authors have read and approved the final manuscript.

\section{Conflicts of Interest}

The authors declare no conflict of interest.

\section{References}

1. Sutton, W.H. Microwave processing of ceramic materials. Cer. Bull. 1989, 68, 376-386.

2. Thostenson, E.T.; Chou, T.W. Microwave processing: Fundamentals and application. Compos. Part A Appl. Sci. Manuf. 1999, 30, 1055-1071.

3. Shelbey, J.E. Introduction to Glass Science and Technology, 2nd ed.; Royal Society of Chemistry: Cambridge, UK, 2005; pp. 27-30. 
4. Chenu, S.; Rocherullè, J.; Lebullenger, R.; Merdrignac, O.; Chevire, F.; Tessier, F.; Oudadesse, H. Synthesis and characterization of tin containing molybdophosphate and tungstophosphate glasses. J. Non-Cryst. Solids 2010, 356, 87-92.

5. Vaidhyanathan, B.; Ganguli, M.; Rao, K.J. Novel method of preparation of inorganic glasses by microwave irradiation. J. Solid State Chem. 1994, 113, 448-450.

6. Ghussn, L.; Martinelli, J.L. A novel method to produce niobium phosphate glasses by microwave heating. J. Mater. Sci. 2004, 39, 1371-1376.

7. Duval, D.J.; Phillips, B.L.; Terjak, M.J.E.; Risbud, S.H. Reversible color changes and structural implications of microwave melting ion-conducting glasses. J. Solid State Chem. 1997, 131, 173-176.

8. Almeida, F.J.M.; Martinelli, J.R.; Partiti, C.S.M. Characterization of iron phosphate glasses prepared by microwave heating. J. Non-Cryst. Solids 2007, 353, 4783-4791.

9. Wang, J.S.; Jeng, J.S.; Ni, C.T. The study on the phosphate glass melted by microwave irradiation. J. Non-Cryst. Solids 2009, 355, 780-784.

10. Vaidhyanathan, B.; Rao, K.J. High microwave susceptibility of $\mathrm{NaH}_{2} \mathrm{PO}_{4} \cdot 2 \mathrm{H}_{2} \mathrm{O}$ : Rapid synthesis of crystalline and glassy phosphates with NASICON-Type chemistry. J. Solid State Chem. 1997, 132, 349-354.

11. Hémono, N.; Chenu, S.; Lebullenger, R.; Rocherullé, J.; Kéryvin, V.; Wattiaux, A. Microwave synthesis and physical characterization of tin(II) phosphate glasses. J. Mater Sci. 2010, 45, 2916-2920.

12. Mandal, A.K.; Sinha, P.K.; Das, D.; Guha, C.; Sen, R. Higher Fe ${ }^{2+} /$ total Fe ratio in Iron doped phosphate glass melted by microwave heating. Mater. Res. Bull. 2015, 63, 141-146.

13. Mandal, A.K.; Biswas, K.; Annapurna, K.; Guha, C.; Sen, R. Preparation of alumino-phosphate glass by microwave radiation. J. Mater. Res. 2013, 28, 1955-1961.

14. Mandal, A.K.; Balaji, S.; Sen, R. Microwave and conventional preparation of Zinc Borate glass: $\mathrm{Eu}^{3+}$ ion as luminescent probe. J. Alloys Compd. 2014, 615, 283-289.

15. Mandal, A.K.; Agrawal, D.; Sen, R. Preparation of homogeneous barium borosilicate glass using microwave energy. J. Non-Cryst. Solids 2013, 371-372, 41-46.

16. Peñaranda-Foix, F.L.; Janezic, M.D.; Civera, J.M.C.; Canós, A.J. Full-wave analysis of dielectric-loaded cylindrical waveguides and cavities using a new four-port ring network. IEEE T Microw. Theory 2012, 60, 2730-2740.

17. Rao, K.J.; Vaidhyanathan, B.; Ganguli, M.; Ramakrishnan, P.A. Synthesis of Inorganic Solids Using Microwaves. Chem. Mater. 1999, 11, 882-895.

18. Mandal, A.K.; Sen, S.; Mandal, S.; Guha, C.; Sen, R. Energy efficient melting of glass for nuclear waste immobilization using microwave radiation. Int. J. Green Energy 2014, doi:10.1080/15435075.2014.895735.

19. Roy, R.; Agrawal, D.; Cheng, J.; Gedevanishvili, S. Full sintering of powdered-metal bodies in a microwave field. Nature 1999, 399, 668-670.

20. Mondal, A.; Upadhyaya, A.; Agrawal, D. Microwave sintering of W-18Cu and W-7Ni3Cu alloys. J. Microw. Power Electromagn. Energy 2009, 43, 11-16. 
21. Wang, L.; Wu, H.; Shen, Z.; Guo, S.; Wang, Y.Enhanced microwave absorption properties of Ni-doped ordered mesoporouscarbon/polyaniline nanocomposites. Mater. Sci. Eng. B 2012, $177,1649-1654$.

22. Wu, H.J.; Wang, L.D.; Wang, Y.M.; Guo, S.L.; Shen, Z.Y. Enhanced microwave absorbing properties of carbonyl iron-doped Ag/ordered mesoporous carbon nanocomposites. Mater. Sci. Eng. B 2012, 177, 476-482.

(C) 2015 by the authors; licensee MDPI, Basel, Switzerland. This article is an open access article distributed under the terms and conditions of the Creative Commons Attribution license (http://creativecommons.org/licenses/by/4.0/). 